\title{
Sleeves or Zigzag Lines: Salary Determination Through Fair Evaluation
}

$\mathrm{T}$ HE classic statement which inevitably appears sooner or later in any discussion of employee relations is, "People are much more interested in how their compensation compares with that of others than in their own compensation as such."

Trite as this statement has become, it is nonetheless true. To have the slightest chance of employee approval, any scheme of compensation must provide a fair relationship between the requirements of the position and the compensation paid to the one filling it. But even more important is the necessity that relationships between salaries for different positions shall be, in proportion, much like the relationships between job requirements.

No reasonable employer would dispute this, but many entirely reasonable employers do have salary discrepancies between positions which cannot possibly be in harmony with the qualities expected in those filling the positions. The reason for this condition is not lack of recognition of the correctness of the principle being violated nor is it intentional discrimination between employees. The reason is, however, that it is usually very difficult to judge, or even to measure, the real job values and to relate them to a valid compensation relationship.

This problem exists in a library, just as it exists in a factory or an office. We may be sure that a chief reference librarian should be paid more than a janitor, but can we be as sure about the relative positions of a searcher, a secretary to the librarian, a skilled tradesman responsible for maintenance, a building operating engineer responsible for the heating and lighting system, the person in the law library responsible for acquisitions, the curator of a small but very important special collection, and the faithful member of a small library staff who knows how to do any of the varied tasks in his organization? And even though such positions can be placed in relative order, can they be placed at a suitable distance from each other so as to determine fairly the correct percentage relationship between their salaries?

It is done some way, of course. The necessity is fundamental, and salary structures are made up, for better or for worse; but it is questionable if any large percentage of those responsible for directing the operation of libraries could say with entire honesty that they know that their salaries are correct and right as they relate each to the other.

Nonetheless, there is a way in which this can be done with reasonable accuracy and by which fairness to staff members may not only be maintained but may also be demonstrated. This is the way of position evaluation. Position evaluation consists, in its simplest terms, of three steps:

I. Listing of the factors which go to make up what we expect in qualities and abilities involved in any position-the things which are paid for when the incumbent is employed. 
2. Determination of the relative values of each factor, and the allocation to each of the number of points expressing this relationship.

3. Analysis of each type of position, giving to each factor in its make-up the number of points indicated by the requirements of the position.

Step number one is not too involved. There are not too many major factors after all. Everything that is expected in a new employee for any type of work may be included under two main headings-preparation and personal qualifications. It is expected that both of these factors be paid for in relationship to the amount of each which is required as a minimum for satisfactory job performance. Once the new employee is on the job it is expected that responsibilities of some sort be given him. Some payment should be made for the assumption of responsibility. And if the employee is working under conditions which are either especially unpleasant or especially hazardous, again he is entitled to have his compensation reflect the degree of seriousness of these conditions.
Within these four basic factors, therefore -preparation required for the job, personal qualifications required for the job, working conditions surrounding the job, and responsibilities required on the job-every element of value for which salaries are computed can be found; and a proper regard for the degree in which each factor is required as a condition of satisfactory work performance will require that compensation finally granted should bear a reasonable relationship to the factors required for the job.

But the reader may well ask how all of this theory can be used in a practical way by a person not skilled in personnel techniques and not familiar with the professional jargon thereof.

Preparation, personal requirements, responsibilities, working conditions-although all will agree that these should be considered, how shall they be used as measuring tools? The following table of factor values provides an answer as developed at the University of Illinois.

\section{Description and Value of Factors Used in Job Evaluation}

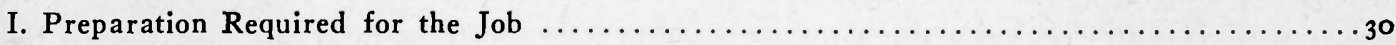

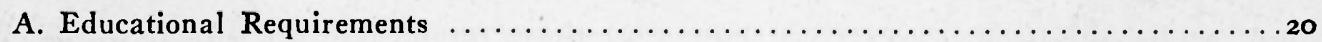

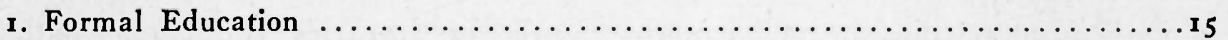

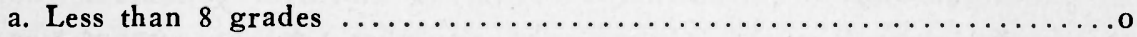

b. Grammar school graduation ...............................

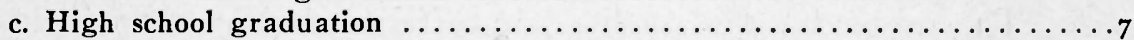

d. High school graduation with requirement for inclusion of special course

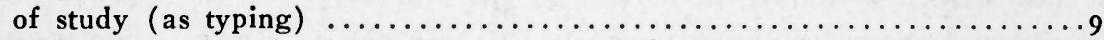

e. College or university degree (Where degree is not required, allow I point

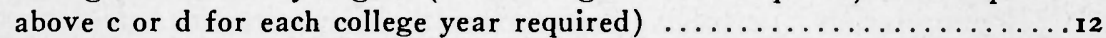

f. College or university degree with requirement for special course of study

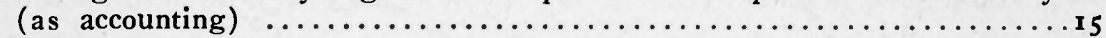
Where more than the minimum required is indicated as "desirable" split the difference between the two levels.

Equivalent training in night school or other special courses to be counted as above.

2. Post graduate or specialized training required beyond or in addition to gen-

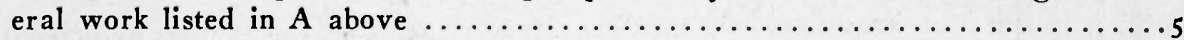

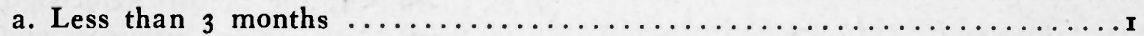

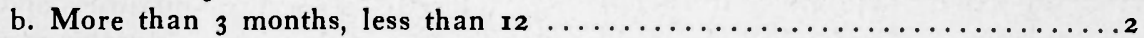

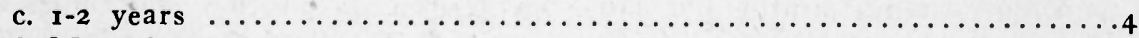

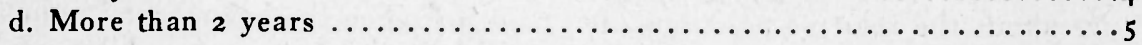




\section{Description and Value of Factors (Continued)}

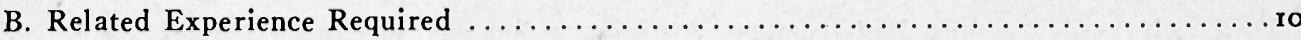

I. Two points per year up to a maximum of ro points for 5 or more years.

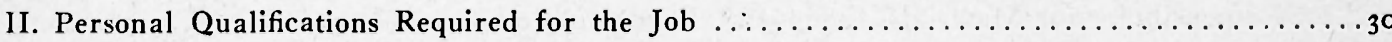

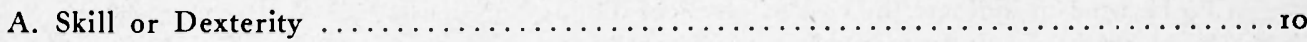

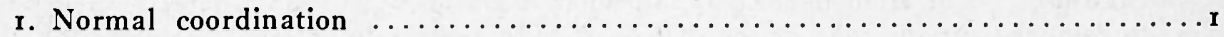

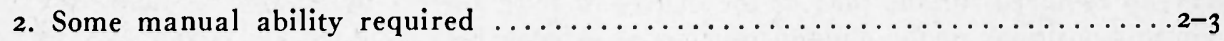

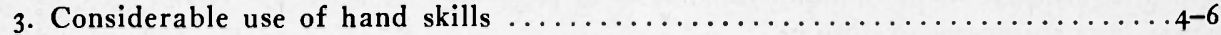

4. High degree of ability to make or do by use of the hands $\ldots \ldots \ldots \ldots \ldots, 7-8$

5. Requirement for extremely fine and precise work $\ldots \ldots \ldots \ldots \ldots \ldots \ldots$ ro

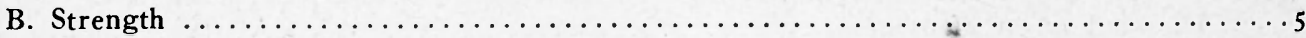

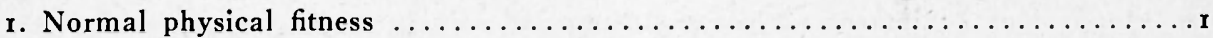

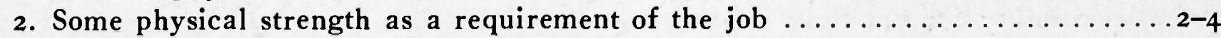

3. Use of considerable physical strength a primary job requirement $\ldots \ldots \ldots \ldots+5$

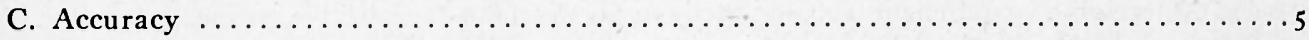

r. Requirement for accuracy, precision, or attention to detail not a factor in the job..o

2. Some requirements for accuracy, precision, or attention to detail to a minor

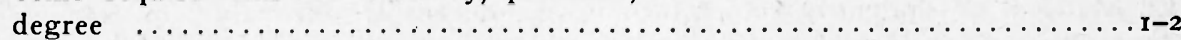

3. Need for considerable accuracy, precision, or attention to detail $\ldots \ldots \ldots \ldots .3-4$

4. Need for strict accuracy, extreme precision, or marked attention to detail ..... 5

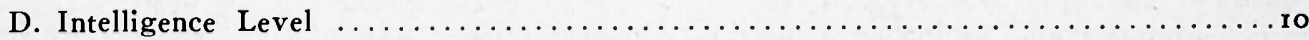

r. Minimum to almost average $\ldots \ldots \ldots \ldots \ldots \ldots \ldots \ldots \ldots \ldots \ldots \ldots \ldots \ldots \ldots, 4$

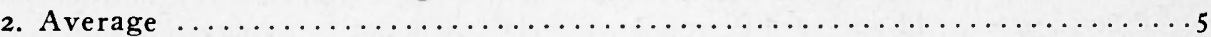

3. Requirement for more than average intelligence, up to necessary for a very

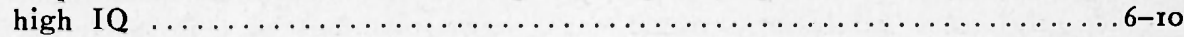

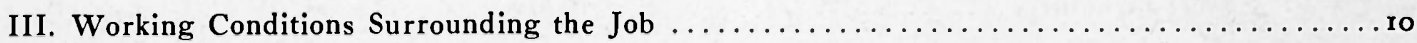

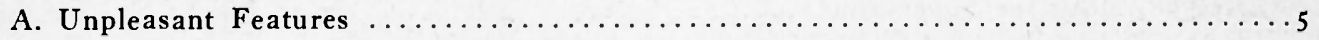

r. Points to be allowed only if conditions of work are abnormally and unusually unpleasant because of material handled, physical surroundings, or the like, with

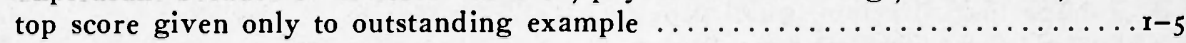

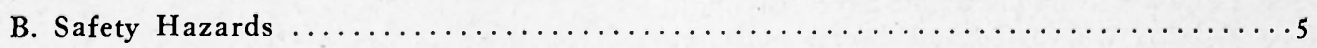

r. Points to be allowed only if working conditions provide some definite degree of

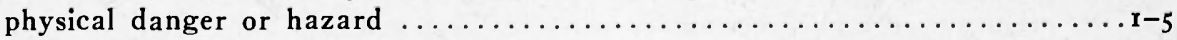

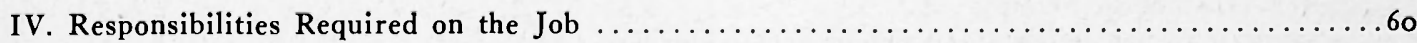

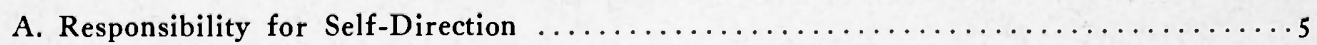

r. Work carried on under a maximum of supervision or review .............

2. Some requirements for dependability without close supervision or review..... r-3

3. High degree of dependability, for work with little or no supervisory check or

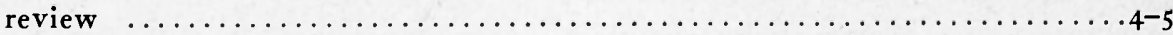

B. Responsibility for Use of Initiative and Independent Judgment .............. 5

r. Work follows regular and clear pattern laid out by supervisor with little or no need for use of own initiative or independent judgment $\ldots \ldots \ldots \ldots \ldots \ldots$ r-2

2. Under direct supervision but with some responsibility for use of own initiative and judgment in carrying out certain details of work $\ldots \ldots \ldots \ldots \ldots \ldots+3$

3. Under immediate direction as to general plans and policies, but with considerable independent freedom of action in developing working procedures...6-ro

4. Within the general framework of departmental or university policy, major responsibility for planning and carrying out work program of the position....r r-15

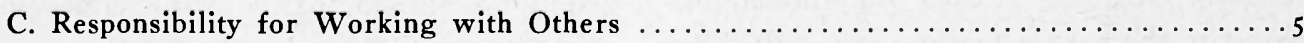

r. Normal work relationships within usual lines of authority with only ordinary

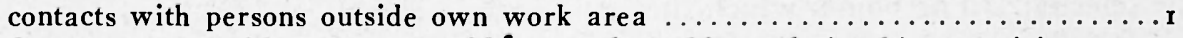

2. Some contacts with persons outside normal working relationships requiring cooperation, tact, and appreciation of other points of view and involving the representation of one's own department in these outside contacts $\ldots \ldots \ldots \ldots .2-3$ 


\section{Description and Value of Factors (Continued)}

3. A large degree of outside contacts involving use of tact, diplomacy, appreciation of point of view of others, or an outstanding degree of teamwork $\ldots \ldots \ldots \ldots+4$

D. Responsibility for Materials, Equipment, Funds, or Personal Safety

( $T o$ be used to indicate the cost of physical damage or the degree of personal harm which would result from neglect or improper use of equipment or materials normally required for the job; or the degree of trust for funds handled or controlled in this position; or the danger to personal safety which would result from carelessness in performance of duty.)

I. No material or equipment subject to damage if neglected or improperly handled; no responsibility for handling money; no reasonable possibility of endangering

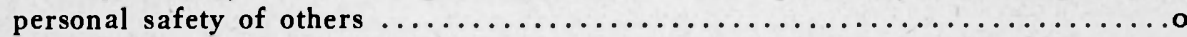

2. Material or equipment subject to damage of very little measurable value; or responsibility for handling small sums of money under close check; or a slight possibility of danger to personal safety if work is carelessly done $\ldots \ldots \ldots \ldots \ldots$ r-2

3. Material or equipment subject to damage of some measurable value; or responsibility for handling considerable money under close check; or safety or welfare of others depends to a measurable degree on this employee $\ldots \ldots \ldots \ldots \cdot 3-5$

4. Material or equipment subject to damage of considerable value; or responsibility for regularly handling considerable sums of money without close and frequent check; or a considerable degree of responsibility for safety and welfare

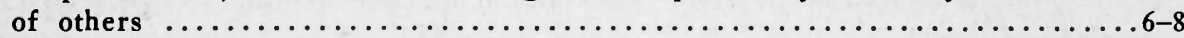

5. Material and equipment subject to damage of great value; or regular and direct responsibility for handling large sums of money under conditions such that errors would not readily or immediately be caught by supervisory check; or direct responsibility for the physical welfare of others to the point where any neglect or carelessness would cause harm to others at least potentially

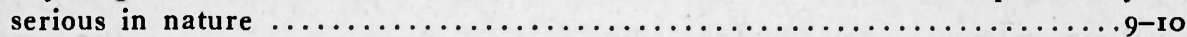

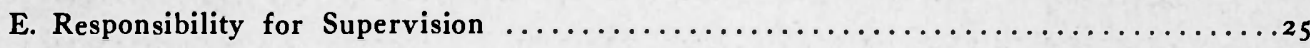

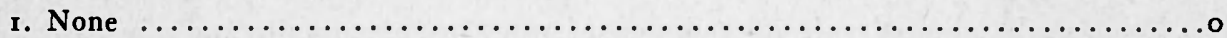

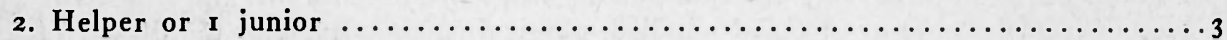

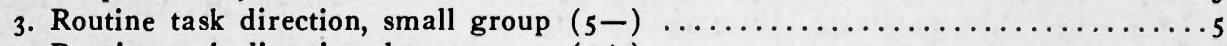

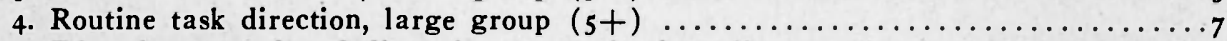

5. Direction varied and discretionary work of small group $(5-) \ldots \ldots \ldots \ldots$

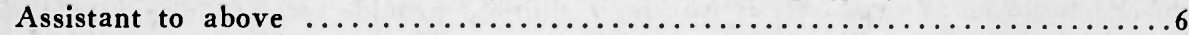

6. Direction varied and discretionary work of large group $(s+) \ldots \ldots \ldots \ldots \ldots$ ro

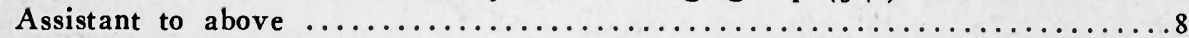

7. Full responsibility small department under (ro-) $\ldots \ldots \ldots \ldots \ldots \ldots \ldots \ldots \ldots$ I5

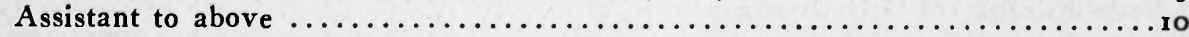

8. Full responsibility large department or division $($ ro + ) $\ldots \ldots \ldots \ldots \ldots \ldots \ldots \ldots$

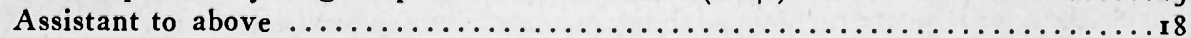

The factors are so broken down and the statements so worded that anyone who knows about the position can do a sound job of evaluating the factors which it requires.

It may easily be tried. A rough copy of the form "Job Evaluation Work Sheet" should be drawn. Any job thoroughly familiar to the person making the evaluation may be selected. The points which the job requires in accordance with the "Description and Value of Factors ..." are filled in column by column. The total points are added and a job evaluation is attained. It should be tried on several jobs, the points for each added, and their totals compared. The totals may then be set down in ascending order. Opposite each should be placed the present salary of the job. If the first attempt is satisfactory and the salary schedules are correctly related, the salary totals should ascend as do the point totals.

If they do not, one of three things may be true: the point in the allocation of point 


\begin{tabular}{|c|c|c|c|c|c|c|c|c|c|c|c|c|c|c|c|c|}
\hline \multirow{4}{*}{$\begin{array}{l}\text { CLASSIPICATION } \\
\text { TITLI }\end{array}$} & \multicolumn{15}{|c|}{$\begin{array}{l}\text { ASSIGNED NUMERICAL VALUES OF EVALUATION FACTORS } \\
\text { (Please Refer to "Description and Value of Factors Used in Job Evaluation" for Detailed Descriptions and Values) }\end{array}$} & \multirow{4}{*}{$\begin{array}{c}\text { TOTAL } \\
\text { POINTS } \\
\text { ASIGNBD } \\
\text { TO THR } \\
\text { CLASSIFI. } \\
\text { CATION } \\
\text { TITLE }\end{array}$} \\
\hline & \multirow{3}{*}{ 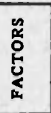 } & \multicolumn{3}{|c|}{ I. Preparation for the Job } & \multicolumn{4}{|c|}{ II. Pereonal Qualificatione } & \multicolumn{2}{|c|}{\begin{tabular}{|c|} 
III. \\
Working Conditione
\end{tabular}} & \multicolumn{5}{|c|}{ IV. Responsibilities Required on the Job } & \\
\hline & & \multicolumn{2}{|c|}{ Educanion } & \multirow{2}{*}{\begin{tabular}{|c|} 
B. \\
Experience
\end{tabular}} & \multirow{2}{*}{$\begin{array}{c}\text { A. } \\
\text { Skill or } \\
\text { Dexterity }\end{array}$} & \multirow{2}{*}{\begin{tabular}{c|} 
B. \\
Strengtb
\end{tabular}} & \multirow{2}{*}{\begin{tabular}{|c|}
$c$. \\
Accuracy \\
\end{tabular}} & \multirow{2}{*}{\begin{tabular}{|c|} 
D. \\
Intelligence
\end{tabular}} & \multirow{2}{*}{\begin{tabular}{|c|} 
A. \\
Ungleasum \\
Peaturea
\end{tabular}} & \multirow{2}{*}{\begin{tabular}{c|} 
B. \\
sateety \\
Hasarde
\end{tabular}} & \multirow{2}{*}{$\begin{array}{c}\text { A. } \\
\text { Sell. } \\
\text { Direction }\end{array}$} & \multirow{2}{*}{$\begin{array}{c}\text { B. } \\
\text { Initietivg } \\
\text { Judemeat }\end{array}$} & \multirow{2}{*}{$\begin{array}{c}c \\
\text { Working } \\
\text { Whith } \\
\text { othere }\end{array}$} & \multirow{2}{*}{ 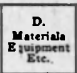 } & \multirow{2}{*}{\begin{tabular}{|c|} 
E. \\
Iuprovidion
\end{tabular}} & \\
\hline & & \begin{tabular}{|l|} 
S. Porman \\
Eduction \\
\end{tabular} & $\begin{array}{l}2 \text { Sppeciel } \\
\text { Trening } \\
\end{array}$ & & & & & & & & & & & & & \\
\hline \multicolumn{2}{|c|}{$\begin{array}{l}\text { EXAMPLE: } \\
\text { Assistant Clerk }\end{array}$} & 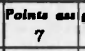 & $0^{\text {ned for }}$ & $\begin{array}{c}\text { Lemomeire } \\
0\end{array}$ & lon purm & oes only & 1 & 4 & 0 & 0 & 0 & 1 & 1 & 1 & 0 & 17 \\
\hline & & & & & & & & & & & & & & & & 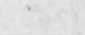 \\
\hline & & & & & & & & & & & & & & & 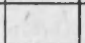 & \\
\hline & & & & & & & & & & & & & & & & \\
\hline & & & & & & & & & & & & 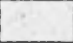 & & & & \\
\hline & & & & & & & & & & & & & & d & 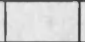 & \\
\hline & & & & & & & & tit & & & cis & & & $x_{1}$ & & 4 \\
\hline & & & & & & & & & & & 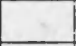 & & & & & \\
\hline & & & & 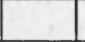 & & & & & & & & & & & & \\
\hline 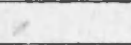 & & & & & & & & & & & & & & & y & \\
\hline ' & & & & & & & & & 3 & . & & & & s. & & \\
\hline & & & & & & & & & & & & & & & & \\
\hline & & & & & & & & & & & & & & & & \\
\hline & & & & & $x_{1}$ & & & & & & & s & & & & \\
\hline & & & 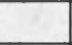 & & & & & & & & & & & 5 & tets & \\
\hline & & & & & & & & & & & & +2 & & & & \\
\hline & & & & & & & & & & . & & T & & & & \\
\hline & & & & & 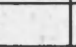 & & & & & 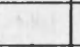 & & & & & E. & \\
\hline & & & & & & & & & & & & & & & & \\
\hline
\end{tabular}

values has been missed, the salary schedule is out of line and should be corrected, or factors other than pure theory are affecting the salary structures.

These three points may be examined in further detail:

I. If there is doubt about the judgment or actual knowledge of the person making the evaluation, someone else should be asked to put down his figures. In the work at Illinois this has been done effectively by supervisors and by those actually doing the job, as well as by the trained staff of the office. While totals may vary, the differences in relationship are surprisingly few. It is hardly necessary to point out, too, that participation by both employees directly concerned and by supervisors of those employees adds greatly to the probability of final acceptance of the end results by both groups.

2. If the person making the evaluation is satisfied that the values are about right, the burden of proof is on him, as employer, to justify salary schedules which do not accord with those values. Suppose there are one hundred different position classifications (these classifications are discussed in detail later) and a diagonal or ascending line or curve has been drawn on a piece of graph paper. Suppose then another line or curve plotting the salaries now being paid is drawn. They will not be exactly parallel; that would be too much to expect. But the salary line should move around within a fairly close "sleeve" above or below the value line, and, as long as it does, the compensation schedule is in good shape.

3. But, when there occurs in the salary line a sharp "zig" below the value line, or an abrupt "zag" above it, then at least questions should be asked: Was the salary for the "zigging" position, perhaps, set there because its incumbent at the time was a young or inexperienced person who was at the minimum of his earning power and worth as an individual? And was the "zag" due to the other situation in which the incumbent was an old experienced employee whose compensation was well above the average because of long life and faithful performance of duty? 
It may be well at this point to discuss what is meant by position classification. A proper discussion of that subject would require a separate article, but it should be underscored and repeated that the whole evaluation scheme has to be based on positions, not people; on what is required to perform satisfactorily the duties of the position, not the merits of the individual himself. The Ph. D. can do janitor work, but it is still a janitor position paying the same rate to the graduate of the third grade in the Fifth Ward School District. So, it is necessary to be concerned with what the position needs, not what the incumbent has, in this part of the discussion.

\section{Supply and Demand}

If this is assumed, the practical administrator still has to take a realistic point of view toward the ideal represented by an exactly parallel relationship between job values and compensation. He cannot ignore, as an outstanding example, the law of supply and demand.

Not long ago the writer made a position classification survey and evaluation for a large library. Its positions were divided into two groups-those requiring a library school degree and those not so requiring. Theoretically, the nonprofessional employee with, for example, thirty-five value points should have had the same salary as the professional with the same number of points, since the totals as arrived at were high for factors required in the nonprofessional positions and low for the same ones in the professional positions, and vice versa. But the prevalent rate in the community, based on supply and demand, was several hundred dollars higher for the thirty-five-point professional than for the thirty-five-point nonprofessional, and that discrepancy existed all along the line between the two groups. It would have been unwise to have insisted on paying the nonprofessional several hun- dred dollars over the local market. It would have been futile to have tried to hire the professional for an amount less than the rate he could get elsewhere in the community. The fact that supply and demand had a controlling effect here was accepted and two separate curves were set up, one for professional and the other for nonprofessional. The relationships within each curve were adjusted without trying to force one to work with the other. Of course, about twelve points might have been allocated for each year of library school, but that adjustment would have been a little dubious as compared to other values for education. It did suggest, however, that a year of library school was a sound investment.

This whole subject is not so complicated as it seems at first glance. It has been presented in simple terms and, actually, it is simple. The schedule of factor values illustrated here does not have to be used. This one has worked in practice, but so do others. The interesting thing is that the results, in order of relationship, tend to be similar with the use of any sensible set of factor values.

What procedure should be followed after the evaluation is made? First of all, the several "zigs" and "zags" should be carefully examined. If there is not some justification for their existence, they should be corrected. If they "zig" below the line, an early increase in salary levels is suggested in order to get up to the line. If they "zag" far above, the next hiring for that type of work should be down near the value line. Although it is not practical to reduce salaries for those now getting too much, a similar situation with new employees can be avoided. Thus, when a new position is established and a salary must be set, it should be examined closely and the salary based on its values. This procedure should lead to an effective personnel practice in libraries. 